\title{
Challenges and Prospects of e-Government implementation in Afghanistan
}

\author{
Abdul Mateen Samsor \\ Innovation, Research and Industry Development Unit, \\ Ministry of Communications and IT, Kabul, Afghanistan
}

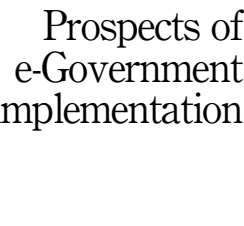

Received 7 January 2020 Revised 8 February 2020 Accepted 10 February 2020

\section{Abstract}

Purpose - The aim of this study is to identify the challenges and barriers to e-Government set up in developing/conflict countries, related to Information Communication and Technology (ICT) and social obstacles - that are common in developing countries like Afghanistan. In today's world e-Government plays an important role of providing easy access to government services that enable citizens in general to communicate faster. This very research concentrates on the implementation of e-Government challenges in developing countries, particularly in Afghanistan. This paper is covering (1) method of study; (2) research strategy; (3) finding and policy recommendation; (4) limitation; (5) theoretical implication; (6) recommendation and conclusion. Additional data related to e-Government in Afghanistan, acquired via a quantitative survey and interviews can also help this analysis.

Design/methodology/approach - This research incorporates both theoretical and empirical study; using both quantitative and qualitative method for data collection. Also, as already noted, the study reviews different literature and academic documents. The original work of the study is the collection of relevant first-hand information for empirical analysis from experts of both public and private institutions such as IT, CIO and management experts through the use of a survey tools. This was done using web-based surveying and delivery of hard and soft copies to the experts to obtain their notions about e-Government implementation obstacles. Finally, both quantitative and qualitative survey results are calculated and presented.

Findings - Empirical study has established that 5 obstacles out of 15 named by respondents, stakeholder involvement, with the highest mean, (4.1145), coordination (4.0038), information sharing (3.9962), ICT literacy (3.9822) and e-Government awareness (3.8830) are considered to be the major obstacles. This opinion was also expressed by the respondents to the in-depth interview which was explained in a paper with detail.

Research limitations/implications - Most research record numerous limitations, therefore, it is important to note that this study is no exception. Some of the limitations were recorded in the course of the study will be counted for the purpose of placing the finding in the right perspective. The limitations of this study were time constraints and difficult to generate enough participation in the survey. Because of that, I did a quantitative survey but could include very few members of top management. Second, the study is limited due to the lack of participation by respondents from various sectors such as citizens, university students, academia, banks, businesses and NGOs. The third limitation was lack of research materials for this study. Many difficulties were encountered with respect to find materials of previous research studies on the topic and in particularly in the context of Afghanistan.

Practical implications - The studies conducted previously on e-Government and referenced herein highlighted implementation challenges in developing countries as a group. Applying this study in Afghanistan may contribute to our understanding of key challenges facing in implementing e-Government process

(C) Abdul Mateen Samsor. Published in International Trade, Politics and Development. Published by Emerald Publishing Limited. This article is published under the Creative Commons Attribution (CC BY 4.0) license. Anyone may reproduce, distribute, translate and create derivative works of this article (for both commercial and non-commercial purposes), subject to full attribution to the original publication and authors. The full terms of this license may be seen at http://creativecommons.org/licences/by/4.0/ legalcode

The author would like to thank Mr. YoungSik Kim (Director, PhaseCommu Corp. and Ex-Professor, KAIST ITTP, South Korea) for his encouragement in the development and publication of this paper. The author has a great pleasure to thank Mr. Sugul Speen (Technical Translator of eNID of Afghanistan) and Mr. Quratullah Hiwadpal (CEO/President at BARYA Consulting Services) for reviewing my paper and providing their input to the development of the paper. Last but not least, I humbly give thanks to my family, who always inspired my studies and supported my work.

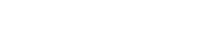

e 
ITPD

5,1

specifically in Afghanistan. The current study contributes some significant findings to the academic field of studying e-Government implementation challenges. It adds the support and information from public and private sector's perspective regarding major challenges in e-Government implementation in Afghanistan.

Social implications - As per looking to the experience of developed and developing countries, this study emphasizes the following key initiatives to be performed in parallel with the running projects by Ministry of communication and IT [18]. 1-Pilot projects, 2-Simplification of Business Processes, 3-A strong committed national leadership, 4-Involvement of Stakeholders, 6-To granting incentives for involvement of local ICT companies, 7-Exemption of basic ICT, 8-To develop a standard ICT infrastructure

Originality/value - Governments around the world are under the pressure from rapid globalization, fiscal, social and technological changes to provide services that are citizen-centric, efficient, transparent, effective, one stop, any time and nonstop. Post-conflict countries are under even greater pressure to create such services because they replace the vacuum caused by the violence and will be the only services offered, rather than simply an upgrade of current government offerings that already meet citizen needs. The adoption of technology is the most efficient way to integrate the public and private sector and to provide services with accountability, transparency and efficiency, but this is not an easy task, especially for developing countries. This research looks at e-Government implementation challenges in developing countries and particularly in Afghanistan. A literature review shows many challenges common among developing countries: a lack of ICT literacy, incomplete infrastructure, a digital divide existing between the rural poor and the emerging urban middle class, an uncertainty about data privacy and data security, the absence of comprehensive ICT policies and legislation, lack of an ICT culture in government and the traditional components of the economy, questions regarding the government's ongoing financial commitment to the project, e-Government awareness, willingness of ministries to engage in information sharing, a void of ICT leadership outside the technologically oriented ministries, resistance to change, an historic lack of intergovernmental coordination and low stakeholder involvement are just some of the many challenges identified. The author belief that developing countries realize the importance of e-Government and consider the implementation of e-Government to be the critical tool for economic stability and growth as well as developing a more transparent, less corrupt government. The survey questionnaires were developed based on the challenges found in literature review. The survey questionnaire was translated into local languages (Pashto and Dari) and an English version served as control indicator by a professional local translator. At first a pilot version was sent to 10 officials from the Ministry of Communication and IT. After attesting period, the survey was circulated to 150 respondents who were experts in various fields such as CIO, Management and IT in Afghanistan. All respondents agreed that stakeholder involvement, coordination, information sharing, ICT literacy, awareness, resistance to change, ICT, finance issues, ICT policy, leadership, data privacy, legislation, ICT culture and digital divide are some of the major challenges for e-Government implementation in Afghanistan. Respondents (3.1412) on ICT security were impartial in their response on whether to include this indicator into challenges. Many projects are run by the Ministry of Communication and IT and within completion of these projects most of the challenges that identified in the analysis of the quantitative survey will be addressed, although the government is also vigorously pursuing legal and policy modifications. As per looking to the experience of developed and developing countries, this study emphasizes the following key initiatives to be performed in parallel with the running projects by Ministry of communication and IT [18]. Pilot projects should be implemented in two ministries as test beds prior to general roll out to ensure the efficient use of money needed for E-government projects. This will have two benefits from one side it will save money in terms of failing projects as argued by $* 19+$ "E-government in developing countries fail, with $35 \%$ being classified as total failures (E-government was not implemented or was implemented but immediately abandoned), and $50 \%$ as partial failures (major goals were not attained and/or there were undesirable outcomes)". On the other hand, in case.

Keywords E-government implementation challenges, Organizational and ICT challenges, Social challenges Paper type Research paper

\section{Introduction}

In general, the concept of e-Government can save time and resources through facilitating communication among the public and government institutions. In the public sector, the terms of digital government, electronic government (e-Government) and electronic governance (e-Governance) are representing the use of Information and Communication Technology (ICT) as a time-needed mechanism for the gathering and dissemination of government information and the delivery of governmental services. These terms are closely related and sometimes interchangeably used. But ITU (2008) distinguished them as following: The digital government is the umbrella term that comprises all types of ICT used in the public sector, 
whereas the e-Government is a must part of digital government. The e-Government refers to the provision of governmental services by ICTs, particularly over the internet to deliver, and receive better public services.

This study aims to investigate the challenges and barriers of implementing e-Government in developing countries. Though, there is a general consensus on the benefits of using Information, Communication Technology (ICT) in public service delivery, but also there exists obstacles in implementing e-Government in developing countries. This paper highlights where major challenges are when a developing country implements its e-Government projects. The paper particularly focuses on Afghanistan and discusses its projects that had chance of implementation in the country. Also, e-Government is a needed feature in today's good governance across the globe to deliver their due duties more efficiently. The e-Government generally provides efficient, transparent, one-stop, 24/7 citizencentric services with responsible, adoptable and updateable technologies. The government's adoption of new technological solutions increases its accountability, efficiency and effectiveness in both public and private sectors. It is assumed that well-implemented e-Government services would result in varieties of improvement to benefit the government and citizenry.

The recommendations are developed with the intentions to provide guidelines on effective implementation of e-Government in developing countries. The study's findings highlight that these challenges are commonly related to organizational factors, ICT literacy and social obstacles, which are often embedded in the prevailing cultures or are exacerbated by prolonged poverty and armed conflict. The study also identifies common tactics adopted by nations who have successfully implemented e-Government, which paved the way for the next generation of emerging countries. This study focuses on challenges of e-Government implementation in Afghanistan, and the review covers the topic of (e-Government implementation challenges in developing countries) from various scholars', which discusses other governments' challenges that they have faced in implementation of e-Government. The study identifies three types of broad challenges in implementing e-Government: (1) Organizational Challenges (2) Social Challenges and (3) ICT Challenges.

The data analysis was to interpret what the survey has collected through qualitative and quantitative measures within Afghanistan's Ministries, which was carried out in 2013. Survey questionnaires were used as an instrument for data collection. Data have been processed and analyzed with the help of MS Excel and SPSS programs. At the end, the study recommends possible solutions in the context of Afghanistan's ongoing e-Government layout. The paper includes a literature review in Section 2. In Section 3, the research framework is discussed with strategy, objectives and data collection procedures. Section 4 highlights the results of this study, and Section 5 concludes the study paper with the discussion on limitations.

\section{Literature review}

The challenges that are hampering e-Government developments can be categorized into three major categories: (1) Organizational Challenges, (2) Social Challenges and (3) ICT Challenges.

\subsection{Organizational challenges}

The role of top management (leadership) is very critical in e-Government implementation in pre-implementation (for financial backing, political support, program awareness and stakeholder endorsement and adoption) as well as post-implementation (for financial sustainability of e-Government projects). Previous research shows that the lack of committed leadership resulted in e-Government implementation failure (OECD, 2013; Zamira Dzhusupova, 2011; UNU-IIST, 2008).
Prospects of e-Government implementation 
ITPD

5,1

Various studies also indicate that resistance to change is one of the critical challenges in implementing e-Government programs, For the resistance, various sources can be found in the current work practices such as paperwork and fear of job loss; others are of the view that e-Government carries potential disruption in a long-established structure, which in turn upsets entrenched bribery and corruption schemes, and eliminates the legacy of system. Not all resistance to e-Government is malevolent; simple inertia plays a role in it. The survey reveals that government officials and the common public are predisposed to change, and many are reluctant to use e-Government as an alternative way of service delivery, particularly when new e-services popped up (Alam, 2007; Ndou, 2004; Zeleti, 2010).

The survey details the indispensability of the collaboration when putting e-Government programs in place that requires collaboration and cooperation at local, regional, national levels, as well as between public and private organizations, for achievement of e-Government goals. E-Government collaboration is to build trust among agencies, citizens and users even where the e-Government program has not penetrated significantly (Rangarirai Matavire, 2010).

According to the findings, one of the core causes of e-Government failure is the lack of stakeholders' involvement at the start of the project. These researchers suggest that the stakeholders' involvement in e-Government projects is very critical from the initial implementation (Zamira Dzhusupova, 2011, Rangarirai Matavire, 2010).

The study shows that an ICT-friendly legal framework is a must for the success of e-Government programs. In many jurisdictions, legislation and regulations that intelligently navigate many issues raised by government use of technology is a challenge due to the presence of few legislators, judges and staff familiar with the subject matter. A need for outside consultants is required to raise (but not resolve) the issues of e-Government forces that leadership is facing. Once the issue is highlighted, it is up to the legislature to prioritize societal interests and develop the laws that allow e-Government to flourish while maintaining the importance aspects of the local social structure (Drljaca and Latinović, 2012; Hwang et al., 2004).

\subsection{Social obstacles}

Research shows that the main obstacles in implementing e-Government are not technical but rather the culture, which is not fully exposed to new technologies. The reason is that e-Government projects in developing countries are frequently outsourced to the private sectors, which may ignore sensitivities to the cultural status quo. It can result in unintended consequences and a gap between the public campaign promoting e-Government and the program as designed (Drljaca and Latinović, 2012; Hwang et al., 2004; Basu, 2004).

Researchers agree that the digital divide is another challenge faced by developing countries when implementing e-Government successfully. Unequal access to information by citizens due to literacy issues, or the price of equipment, transportation or communications services, has been recognized as an important factor in the failure of e-Government adoption (Tele-community, 2012; Rangarirai Matavire, 2010; Dada, 2006).

Other Studies by Ali and Khan in 2009 and Qisar in 2010 show that lack of awareness of know-how causes e-Government programs to fail. Researchers refer to the experience of Bangladesh and Botswana, which had poor awareness of programs before the implementation of e-Government projects. These researchers insist that a comprehensive awareness campaign is required before implementing the e-Government program to be successful (Qaisar and Khan, 2010; Khan, 2009).

Researchers agree that lack of ICT literacy is the main obstacle hampering e-Government implementation, particularly in developing countries where the ICT literacy rate is very low (Nkwe, 2012; Zeleti, 2010; Weerakkody et al., 2009). 
2.3 ICT obstacles

Researchers agree that a proper IT infrastructure should come first for a successful implementation of e-Government programs and add that this is one of the key challenges in developing countries where people do not have proper access to the Internet, electricity or computers (Rangarirai Matavire, 2010).

Studies show that many developing countries see financial support as a critical challenge in the development and implementation of e-Government because it is costly and requires continued funding. The resources availability must be considered in order to that the program be sustainable and reliable on which program success depends (Al-Rashidi, 2010; OECD, 2013; Drew, 2010).

Researchers agree that the lack of a proper policy for e-Government implementation hampers e-Government implementation in developing countries and insist that the availability of clear policy and legal framework for e-Government implementation is critical (Dardha, 2004).

Regarding security, researchers also agree that in developing countries, people hesitate using E-Government because of data insecurity and privacy concerns, particularly in the transaction stage. People consider disclosure of personal information (such as name, picture, date of birth, ID number and credit card detail) to the government through websites and applications that lack security and suspect misuse (OECD, 2013; Nkwe, 2012).

\section{Afghanistan status in United Nation e-Government survey}

There are agencies which regularly conducts online e-Government surveys, such as the United Nations Department of Economic and Social Affairs "UNDESA", United Nation Public Administration Network "UNPAN" and WASEDA University. The WASEDA University, located in Japan, usually selects countries according to particular criteria. The United Nation Department of Economic and Social Affairs "UNDESA" and UN Public Administration Network "UNPAN" usually perform an online survey every 2 years, covering 193 countries (United Nation, 2012, 2014 and 2016).

The survey methodology considers three perspectives (Scope and Quality of Online Services, Telecommunication Connectivity and Human Capacity). The research team looks to each country's national website as well as the website of the Ministry of Education, Labor, Social Services, Health and Ministry of Finance. Associated portals and subsidiary websites are considered in part and parcel of the parent sites and taken into consideration when assigning values to survey responses. The period for assessment of given country depends on their online services, particularly how much contents and functionality are on the websites. A researcher usually reviews one or two countries per day. After initial assessment it's viewed by the senior researcher and incase of any doubt will be approved by the team leader (United Nation, 2012, 2014, 2016).

The consequence of e-Government survey comparison in Figure 1 shows that e-Government development index of Afghanistan was 168 and e-participation is 127 in 2010; E-Government development index was 184; and e-participation index was 89 in 2012. E-Government index was 173, and e-Participation index was 152 in 2014. E-Government index was 171, and e-participation index was 104 in 2016. E-Government index was 177, and e-participation index was 145 in 2018. E-Government index was 169, and e-participation index was 118 in 2020 survey. So, we can conclude that e-Government development index was better in 2010 and 2020 compared to other years' survey which result and similarly e-Participation index that was better in the 2012 and 2020 survey. This is a good sign for democracy improvement and technology adoption in Afghanistan (United Nation, 2010, 2012, 2014, 2016, 2018, 2020) (see Figures 2-3).
Prospects of e-Government implementation 


\section{ITPD}

5,1

\section{6}

Figure 1.

Afghanistan status in UN e-Government survey $(2010,2012$, 2014, 2016, 2018, 2020)

Figure 2.

Afghanistan status in UN e-Government survey $(2010,2012$, 2014, 2016, 2018, 2020)

Figure 3.

Afghanistan status in UN e-Government survey $(2010,2012$, 2014, 2016, 2018, 2020)

\section{Research framework and data collection}

This research incorporates both theoretical and empirical studies; using both quantitative and qualitative method for data collection. Also, as already mentioned, the study reviews different literature and academic documents. The original work of the study is the collection of relevant firsthand information for empirical analysis from experts of both public and private institutions such as IT heads, CIOs and management experts through the use of survey tools. This was done using web-based surveying and delivery of hard and soft copies to the experts to obtain their notions about e-Government implementation
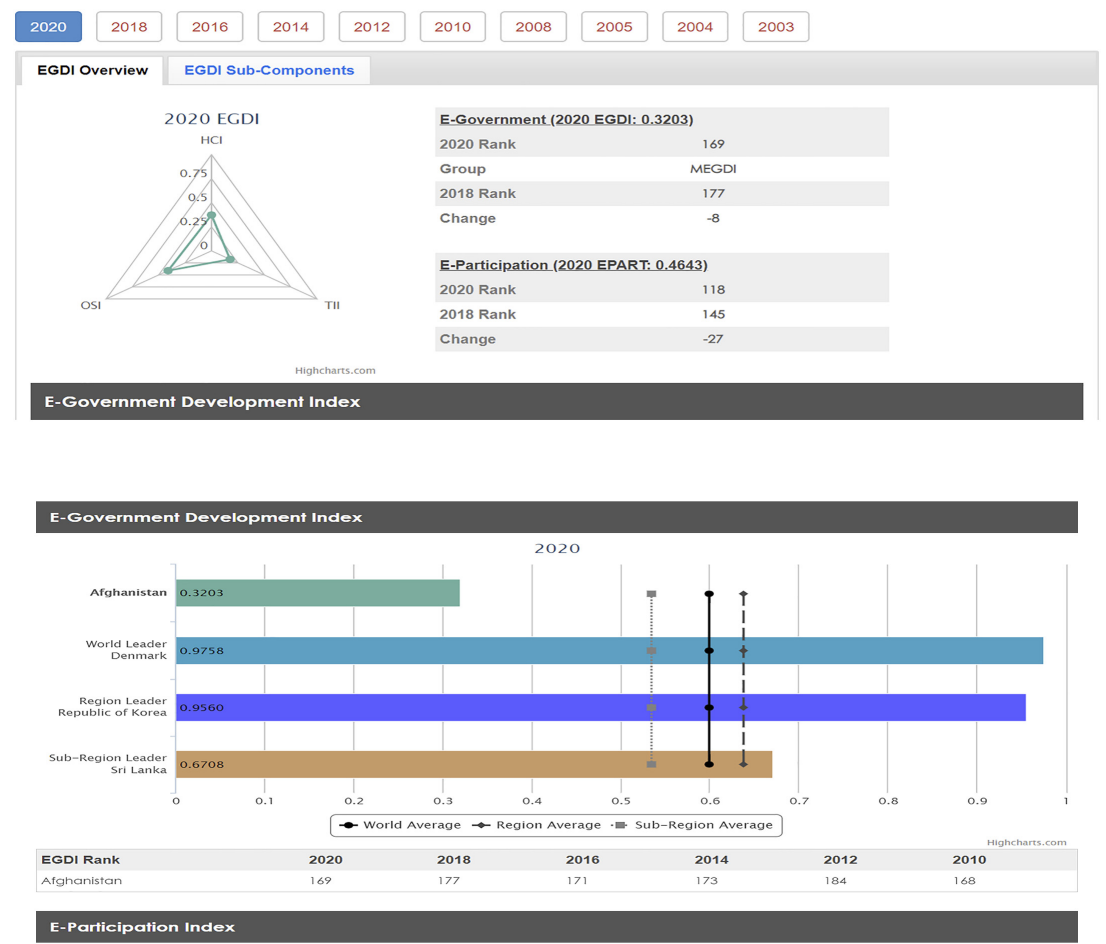

E-Participation Index

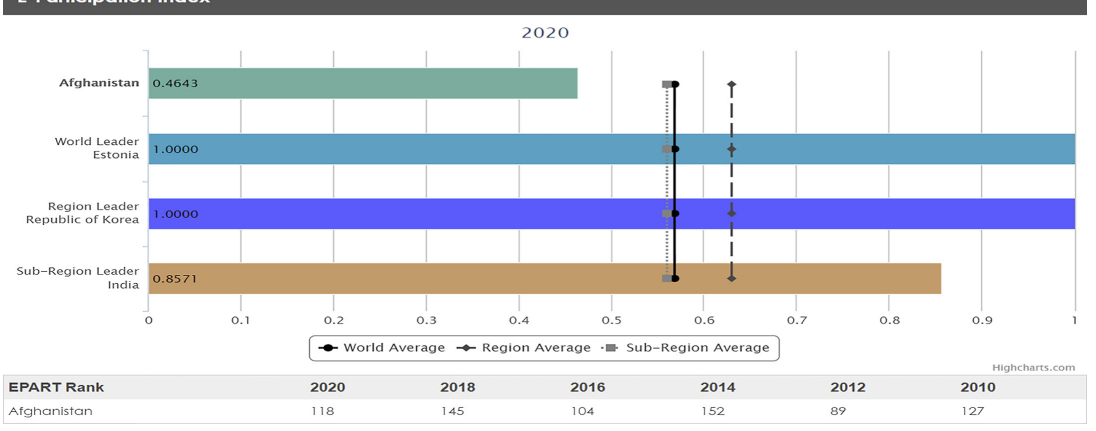


obstacles. Finally, both quantitative and qualitative survey results are calculated and presented.

\subsection{Research strategy}

The main research question of this paper is "What are the challenges to e-Government implementation in Afghanistan?" The answer to this question lies in the responses to "what" question in the survey. In a developing country like Afghanistan, Information Sharing (IS) has not been introduced yet in many sectors, including those where e-Government development is at its initial stage. Most people are not familiar with the idea of e-Government.

This research is based on both quantitative and qualitative approaches along with the use of questionnaires as a survey tool. They are well suited to this research, because the survey is non-experimental and allows descriptive analysis. The quantitative information is provided by a survey, which can be analyzed statistically. Respondents with similar backgrounds are asked the same series of questions for the quantitative research.

\subsection{Conceptual framework}

The basic assumption is that e-Government is a highly effective platform for developing countries that can facilitate an efficient, responsive, transparent and accountable government. From the literature review, it was discovered that developing countries have many challenges that hamper the successful implementation of e-Government.

This study categorizes such challenges into three groups: (1) organizational obstacles, (2) social obstacles and (3) ICT obstacles are shown in the conceptual framework below (see Figure 4).

The study aims to view common challenges and barriers in implementing e-Government in post-conflict and developing countries. Such factors are related to organizational, ICT and social obstacles that arise while implementing e-Government in developing countries like Afghanistan. The findings and recommendations of this study are meant to help governments, particularly MCIT in Afghanistan, to overcome the challenges and barriers that may exist during e-Government implementation.

The specific objectives are as following:

(1) Identify e-Government implementation challenges in Afghanistan.

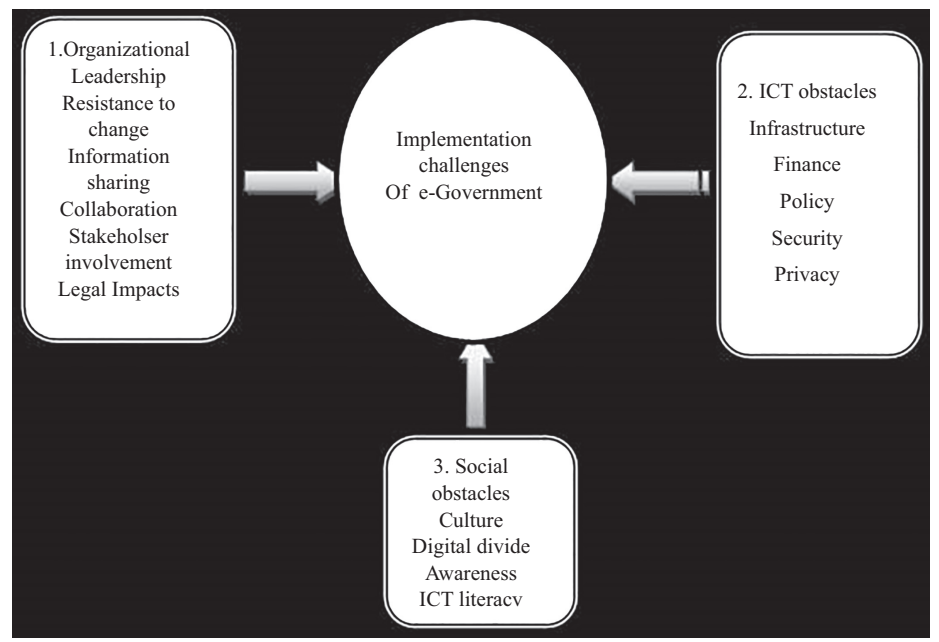

Prospects of e-Government implementation 
ITPD

5,1
(2) Identify e-Government challenges in developing and post-conflict countries.

(3) Discusses implications and develop recommendations to the Government of Afghanistan.

MCIT is implementing e-Government initiatives based upon a strategic master plan for Afghanistan (MCIT, 2013) developed with the help of Macau/China-based United Nations University "UNU-IIS" . This author's study is initiating to investigate what e-Government challenges could we expect in Afghanistan, and how, based on other nations' experiences, these challenges could be addressed. The research questions were what challenges we faced in implementing e-Government in Afghanistan and how we could overcome these barriers. This study emphasizes the following key initiatives to be performed in parallel with the running projects by the Ministry of Communication and Information Technology, the discussion is summarized in the following eight important points.

(1) Pilot projects should be implemented in two ministries as a trial prior to general roll out to ensure the efficient use of money needed for e-Government projects. This will have two benefits, from one side it will save money in terms of failing projects as argued by Heeks (2003) "e-Government in developing countries fail, with $35 \%$ being classified as total failures (e-Government was not implemented or was implemented but immediately abandoned), and $50 \%$ as partial failures (major goals were not attained and/or there were undesirable outcomes)". On the other hand, in case of success, it will help building trust and awareness among citizens and public employees.

(2) Simplification of Business Processes "BPR [1]": in two ministries as best case for others. The government processes are sometimes legacy manual ad hoc procedures and it's often difficult to integrate technology into these non-standard practices. Business process mapping and redesigning will enable standardization of efficient practices, which can then become part of an automated solution for the affected ministry and its constituents.

(3) A strong committed national leadership, as experienced in South Korea (which ranks number one in e-Government Index "e-GDI" in the world) allows Korea to enjoy a better economy with low unemployment. The rationale for strong committed leadership under the highest executive authority is largely political; one agency cannot push another agency to integrate its services using ICT unless there is an understanding that the integration is a priority at the highest levels of the nation's hierarchy.

(4) Involvement of the stakeholders, from academia, banks and NGOs, and, wherever needed, develop a Public-Private Partnership (PPP) model. This will help to speed-up e-Government development and as well as help financial sustainability of the projects.

(5) Granting incentives for the involvement of local ICT companies through the provision of subsidies and others, this can help in improving ICT culture, capacity development, awareness and the ICT competitive environment that may result in creating new initiatives.

(6) Exemption of basic ICT equipment from all taxes, which will help in decreasing ICT equipment prices in the market resulting in greater affordability at the lower end of the economic spectrum, greater ICT literacy and higher e-Government adoption.

(7) To develop a standard ICT infrastructure that can be used by all governments. As e-Government matures and the adoption increases, the pressure on infrastructure increases many folds. Therefore, it is recommended that a strong and standard 
infrastructure must be built from the start, as replacing it (or trying to reverse engineer an integrated solution) in the future will be very difficult.

(8) Adding ICT training into the school curriculum as must, starting during high school era or even a little before. Afghanistan is a country suffering the impacts of a prolonged and brutal conflict. Lacking capital and infrastructure, the country's best hope of employment for the post-conflict generation is in the global ICT sector. As the key tool of economic and social development, it is critical that Afghanistan's youth are well trained to participate in this drive of global jobs and economic growth. Also, using ICT will expose the previously isolated Afghan youth to the ideas from outside the country, avoiding isolation.

(9) The laydown foundation for an ICT free market competition, lowering Internet prices and by increasing Internet speed to accelerate Internet penetration rapidity, subsiding new ICT startups; and pave ways for the ICT industry, which could help job creation in Afghanistan and public would have access to information.

\subsection{Data collection procedure}

The research focuses on technological, organizational, political, internal and external factors impacting e-Government. The purpose of this study is to examine the current stage of implementation of e-Government in Afghanistan. Which obstacles are key contributors to the failure of such initiatives? What are the solutions and recommended courses of action that can be deduced from the successful programs in similar countries?

This study will help the Ministry of Communications and Information Technology "MCIT" to better plan how best such obstacles can be addressed. The study also intends to help in giving policy direction for the effective implementation of e-Government elsewhere. The scope of the study is not global but draws upon experiences in developing countries around the world in an effort to identify those tactics that facilitate e-Government, improve efficiency and transparency in government operations. The study also tries to identify the main obstacles to implementing e-Government in developing countries and particularly in Afghanistan. The study compares the result of empirical study findings and previous researchers' findings, and finally offers solutions and guidelines to MCIT's for successful implementation of e-Government and users of such services. In this part of our research, we have sampled the users of e-Government in several categories according to their professional background.

The sampling plan for this research was directed at the government and private sector in Afghanistan using experts from Information Management, Information Technology and management and administrative organizations as a base for analysis. Overall, 150 individuals were included in the sample size; with a target of population experts from the public and private sectors.

\section{Research results}

\subsection{Survey results}

The quantitative survey questionnaires were translated into two national languages (Pashto \& Dari) along with an English version which was used as a control indicator. The questionnaire consisted of 37 questions based on Likert scale order. Questionnaires were sent to 150 experts from public and private sectors on Feb. 2013, to people holding titles such as CIO, management/ administrative head, IT professionals and midlevel officers as total of 131 experts participated in this survey (Appendices I and II Survey Questionnaires Samples). The demographic information of respondents is categorized as shown in the following figure (See Figure 5).
Prospects of e-Government implementation 
ITPD

5,1

60

The figure above shows the number and percentage of respondents from various perspectives (i.e. number of respondents by gender, position/title, organization and expertise).

The table below shows the respondents' feedback to the questionnaires based on the subject matter of the question. The respondents considered stakeholders involvement, intergovernmental coordination, information sharing, ICT literacy, awareness, resistance to change, ICT infrastructure, financial issues, ICT policy, leadership, data privacy legislation, ICT culture and the digital divide as major challenges to successful implementation of e-Government in Afghanistan. ICT security (mean 3.1412) was not considered to be a major challenge as most of the respondents believed that it is neither ignored nor a key focused challenge as shown in below table (see Tables 1-2).

The reliability among the variables is 0.799 , which is a good indicator of internal consistency among the variables.

Most of the relationship among different variables of the frameworks is positive as shown in Table 3. Highest correlations exist between coordination and ICT culture (0.521), ICT infrastructure and literacy (0.543), ICT culture and literacy (0.516), ICT culture and privacy (0.490). Similarly, there are negative correlations between policy and resistance to change (0.010), legislation and privacy $(-0.019)$ and digital divide and awareness $(-0.12)$.

\subsection{Qualitative survey result}

The interviews were conducted in four entities (three ministries and one company) with the involvement of top management (such as at the director level or above) from the Ministry of Communication and IT; Ministry of Labor Social Affairs Martyrs and Disabled; Ministry of Agriculture Irrigation and Livestock; and Pro-Tech ( a private IT company). The interview almost took $30 \mathrm{~min}$ and discussed implementing e-Government challenges in their respective organizations as shown the interview protocol of Appendix 2.

In response to a leadership questions, all respondents agreed upon the absence of effective leadership that an e-Government cannot be successful in Afghanistan, unless strong leadership lead the ICT initiatives. The interviewees also agreed upon the program vision that accounts for political and administrative issues will inevitably play a central role in designing and implementing e-Government. All risks related to an e-Government project will likely be properly managed, if the leadership is well versed and savvy enough to foresee management and political roadblocks, which can design plans to avoid them. All respondents strongly believed that a strong leadership is always required for a successful implementation of an e-Government.

Concerning resistance to change, most of the respondents did not believe that inertia is a main challenge, although they agreed this factor cannot be ignored. Most of the respondents

Figure 5.

The categorization of demographic information's respondents

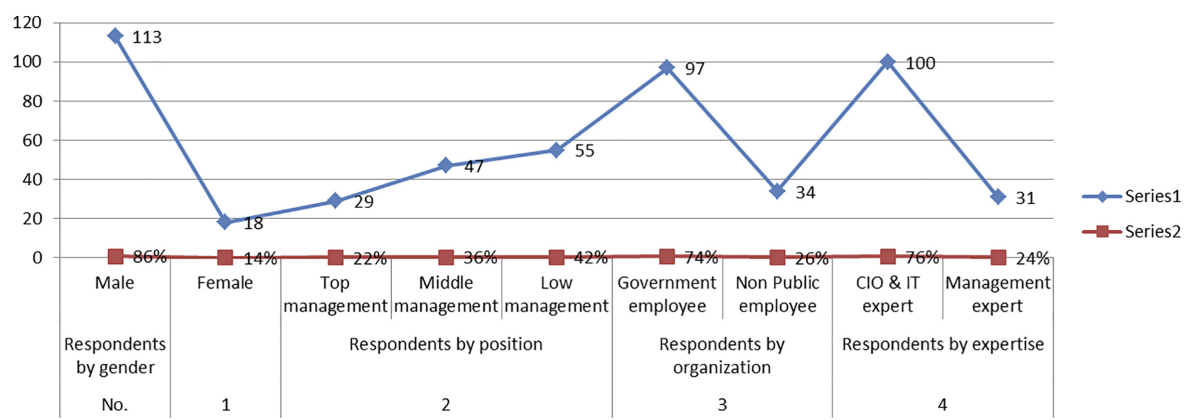




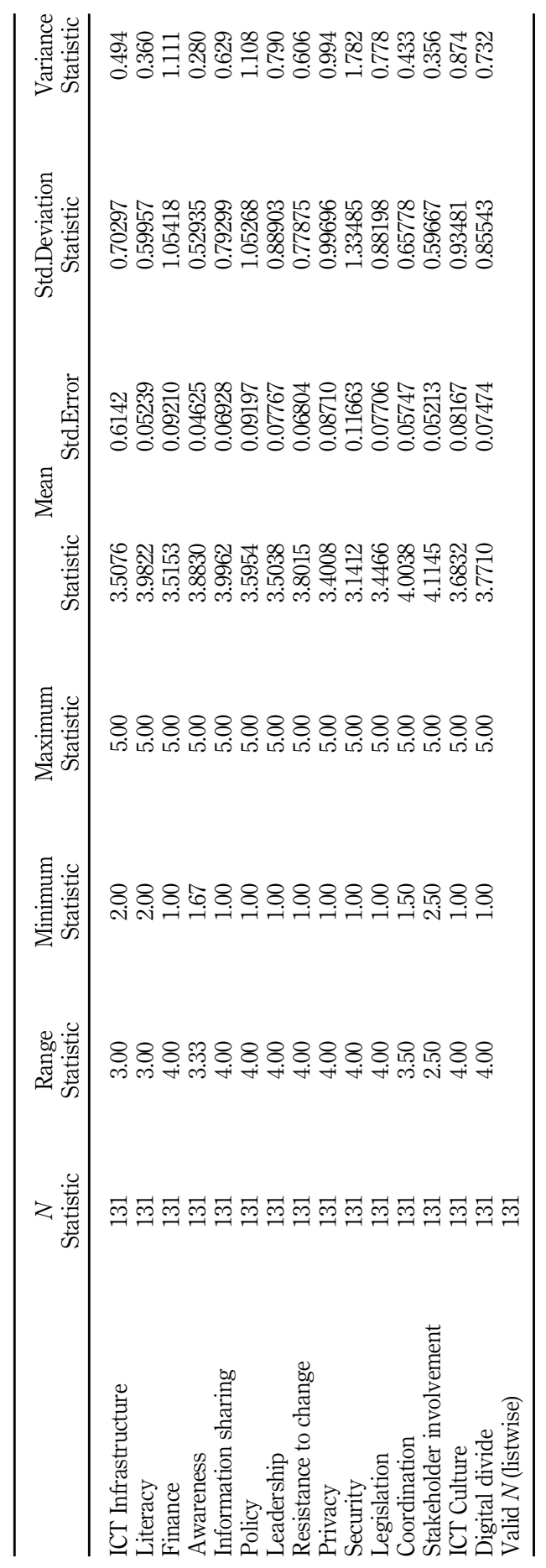

Prospects of e-Government implementation

Table 1. Descriptive statistics 
ITPD

5,1

\section{2}

believed that once proper ICT and e-Government mechanisms are in place, then resistance will not be a major challenge to implementing e-Government in Afghanistan.

Information sharing (IS) was considered to be a very sensitive area in implementing e-Government. Without effective IS between different stakeholders of e-Government, implementing e-Government will never be successful, as interviewees consider it. The interview respondents expressed that the level of information sharing is insufficient to support implementing e-Government's demands for success. Similarly, many interviewees believe that the level of trust between different government organizations is typically not high in a post-conflict environment, if reconciliation processes are not established this will interfere with the success of any program in a nation, such as Afghanistan, that is emerging from decades of war. Given the perceived need for IS to successfully launch an e-Government project, many interviewees viewed this as a major stumbling block in near-term of e-Government success in Afghanistan.

Literacy is also considered to be important factor as it drives the people toward the knowhow of technology. Most of the respondents believe that literacy is a must so one can benefits from e-Government. This is particularly the case with ICT literacy, according to the respondents.

In response to the Awareness factor, most respondents believe that awareness of e-Government among agencies and citizens is very low, and this may result in a failed launch of e-Government projects in Afghanistan. Since e-Government includes array of many diverse agencies, strong e-Government awareness is required for efficient deployment; otherwise, efforts will be wasted and duplicated. Some respondents pointed out that awareness among major stakeholders in an e-Government implementation is insufficient to achieve successful e-Government implementation in the country.

Concerning stakeholder involvement, there was a consensus among interviewees that obtaining such involvement while so many other Afghan institutions are in flux of a major challenge in e-Government implementation in Afghanistan.

Finance was seen as the core pillar of success in implementing e-Government in Afghanistan. The issue is not just the initial funding of equipment and software; but the ongoing maintenance of the systems and training of personnel that concerns the interviewees. Every respondent believed that non-stop availability of funds is a major challenge implementing e-Government to succeed in Afghanistan.

A Digital Divide factor was also considered a major barrier in successful e-Government implementation in Afghanistan. All respondents believed that without having widespread ICT knowledge, citizen participation will not improve under the e-Government and that such knowledge is currently helping only by the affluent. To overcome such a challenge, free ICT education should be improved in every sector of Afghan society.

ICT culture is deemed to be a challenge for a successful e-Government implementation. ICT (other than mobile voice service) has yet to become part of the daily lives among most Afghans. Most of the respondents believe that in Afghanistan ICT and e-Government are in the initial stages and it will take time for ICT to become part of the Afghan culture.

The legislation factor plays a vital role in implementing e-Government. Most respondents believe that e-Government implementation starts by placing the legislation process first. Without legislation, ICT and e-Government have no official standing under the national

Table 2.

Reliability statistics

Cronbach's Alpha Cronbach's alpha based on standardized items

$N$ of items 


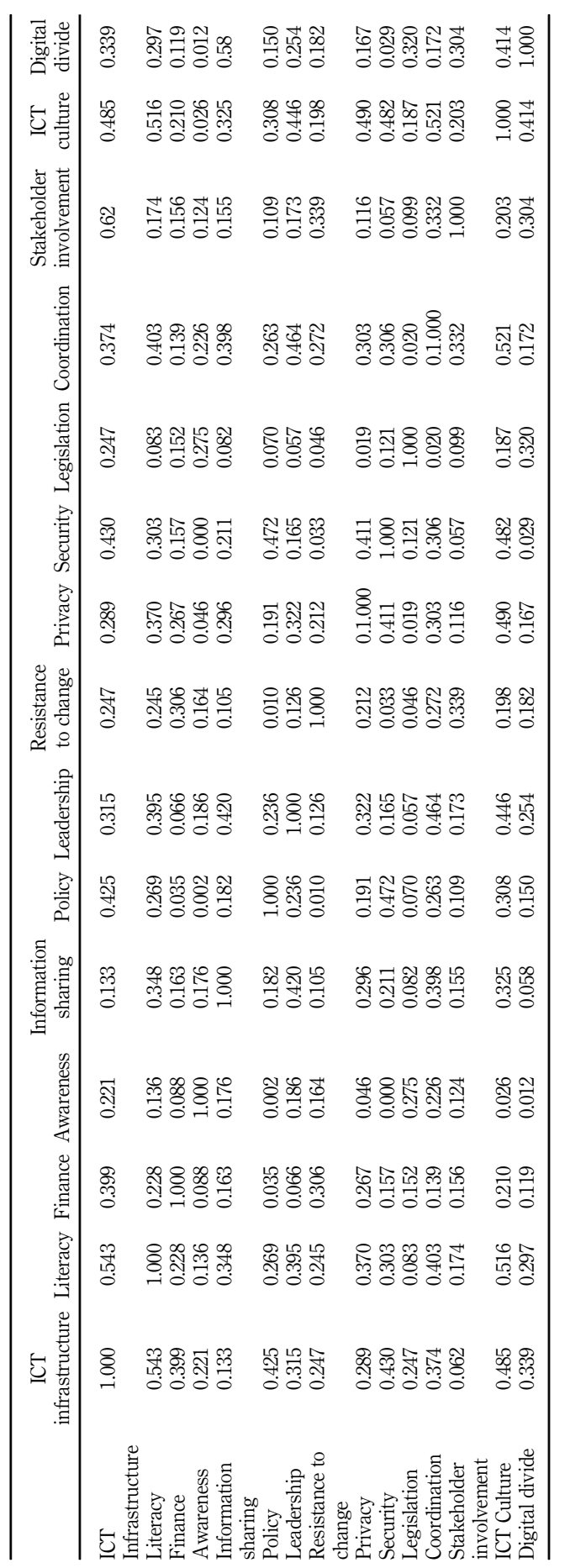

Prospects of e-Government implementation

Table 3. Inter-item correlation matrix 
ITPD

5,1

\section{4}

laws, so it is of great importance that comprehensive e-Government legislation is passed quickly.

As respondents indicate that coordination plays a central role in e-Government implementation. They said proper coordination among project stakeholders of e-Government, much like IS (Information System), is always needed for efficient implementation. Respondents believed that proper and smart coordination mechanisms would help in the success of e-Government. Interviewees argue that policy factors are to be considered as significant barriers to success. Most of the respondents believe that implementing e-Government starts with enacting enabling policies. Without legislation or policy enactment, ICT and e-Government would grow without legal context or social priority. In turn, such shortcomings in the above may support public views of insecurity and lack of support for such initiatives.

ICT Infrastructure, on the other hand, is not viewed as a major stumbling block to e-Government successes. Most of the respondents believe that there is already enough infrastructure in place, so it will not be a major problem for implementing e-Government.

Privacy plays an important role in e-Government implementation. Most of the respondents believe that without the Act-of-Privacy (AOP) people cannot trust e-Government. To get public confidence ICT and e-Government should enact AOP to user advantages.

The Security of the ICT application is also considered as an important factor. The e-Government applications which are based on different layers, such as presentation, business and data must be secured so that everyone gets assured that their data is securely modified, as most respondents said so.

\subsection{Summary}

Following is the summary of data analysis finding based on both quantitative and qualitative surveys. The goal of this study is to evaluate implementation challenges in Afghanistan from the perspective of experts in both public and private sector organizations. Statistical analysis was made from respondents' views and concentrated upon the major 5 obstacles out of 15 , including Stakeholder Involvement (which had the highest mean 4.1145), Coordination (with a mean of 4.0038), Information Sharing (with mean of 3.9962), ICT Literacy (with a mean of 3.9822) and e-Government Awareness (with mean of 3.8830). The qualitative survey respondents showed similar results and agreed that the following five factors are the focal challenges in successful implementation of e-Government in Afghanistan (see Figure 6).

\section{Mean Statistic}

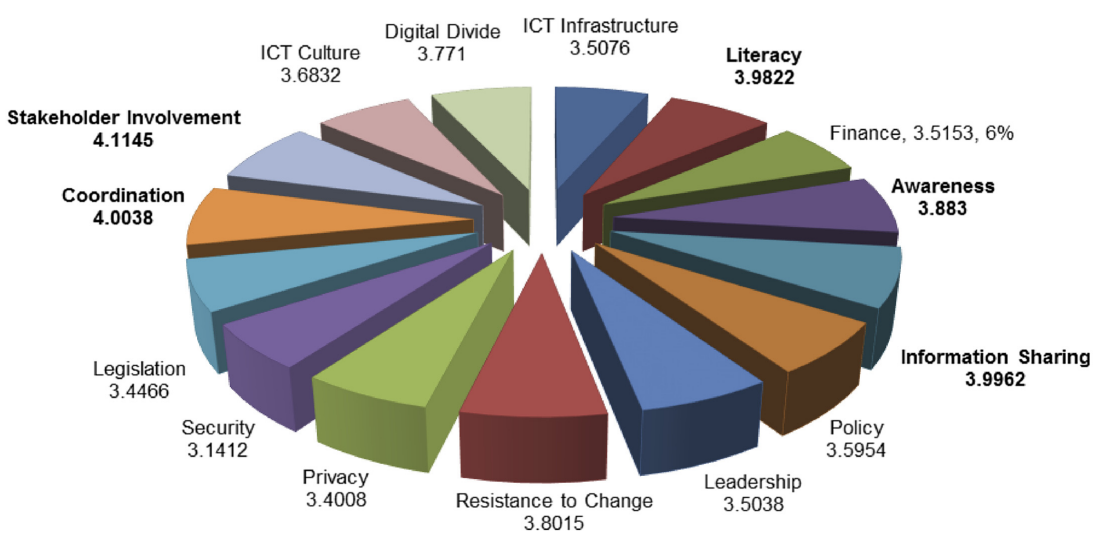

Figure 6.

Summary of finding and data analysis 
In consideration of the above five key challenges, I personally believe that, only addressing/ considering the above-mentioned factors would not be enough for success of e-Government in the country, in addition (to these factors), organizational culture, employees mindset change, process re-engineering and job security would be others critical challenges for the successful implementation of e-Government in Afghanistan and developing countries as well.

The analysis of Afghanistan's e-Government initiatives which are discussed below includes Strengths, Weaknesses, Opportunities and Challenges (SWOC) derived from the Ministry of Communication and IT website, particularly the e-Government Strategy orchestrated by United Nation University" UNU-IIST" and the literature (MCIT, E-Government Strategy; UNU-IIST) (see Table 4).

\subsection{Discussions}

This study starts with the theoretical background (Literature review) and analyzes the challenges of implementing e-Government in developing countries. Several challenges were found through the literature review, but they can be categorized into three major groups: Organizational obstacles [2], social obstacles [3] and ICT obstacles [4]. The current study also found some challenges as mentioned in the e-Government strategy of Afghanistan such as "cost of telecommunications, delivery of government e-services to citizens in a remote areas, lack of technical and human resources for e-Government coordination and implementation, literacy and acceptance of e-Government in the public sector and society, the privacy of information and Freedom of Information issues" (MCIT, e-Government Strategy, https://mcit. gov.af/node/7056).

\footnotetext{
Strength

(1) Leadership

(2) National development policies and strategies

(3) Key ICT/e-Government running projects

(4) Many ICT projects in pace at many agencies

(5) Enhancement of capacity development in organization

(6) Increasing number of ICT department in ministries/agencies

(7) Creating three new departments under MCIT, i.e. e-Government, IT innovation and Cyber Security Directorates

(8) Growing number of web portals in both Government and private sector Opportunities

(1) Rapid growth of mobile and Internet services

(2) High demand and expectation of public to increase transparency and deter corruption

(3) Willingness of external stakeholder to be a partner in implementation and research

(4) Basic infrastructure and legal base for e-Government to be placed soon

(5) Increasing number of ICT institutions

(6) Willingness' of youths in ICT education

(7) Realization of ICT role in daily work
}

Prospects of e-Government implementation 
ITPD

5,1

Consensus exists among the respondents to our survey and interviews that stakeholder involvement, coordination; information sharing, ICT Literacy, e-Government awareness, resistance to change, digital divide, ICT culture, policy, financial continuity, infrastructure, leadership, legislation and privacy are major challenges of e-Government implementation in Afghanistan.

\section{6}

\section{Finding and policy recommendation}

Empirical study has established 5 obstacles out of 15 named by respondents, stakeholder involvement (with the highest mean, 4.1145), coordination (4.0038), information sharing (3.9962), ICT literacy (3.9822) and e-Government Awareness (3.8830) are considered to be the major obstacles. This opinion was also expressed by the respondents in in-depth interview which was explained above (see Figure 7).

Stakeholder involvement is critical for success in implementing e-Government. The importance of stakeholder involvement is also mentioned in the e-Government strategy of Afghanistan "Consultations and partnership with relevant stakeholders and experts, including administrative agencies, industry representatives, academia, and the general public are essential for e-Government strategic planning and implementation" (MCIT, E-Government Strategy). The Ministry of Communication and IT should involve stakeholders from the beginning of any e-Government project, perhaps through formal or informal meetings and discussion, including the use of email, chat rooms (Skype and Yahoo, Google), video conferencing and social media (Facebook and Twitter). These ongoing public discussions will help improve e-Government awareness which is also a very critical factor in the development of e-Government.

Coordination is the second major obstacle found in the analysis. The Ministry of Communication and IT should be home to a strong and active coordination department which should identify and coordinate internal and external stakeholders for all e-Government projects and activities. Effective coordination will include the usage of mobile, email and formal and informal communication. Also mentioned is the importance of coordination, which many consider the major challenge to the success of the e-Government strategy of Afghanistan (MCIT, e-Government Strategy).

Information sharing is indicated in the analysis as a third major obstacle. The government should share general information with the public. It can be shared through the use of both

Figure 7.

The most major five challenges factors

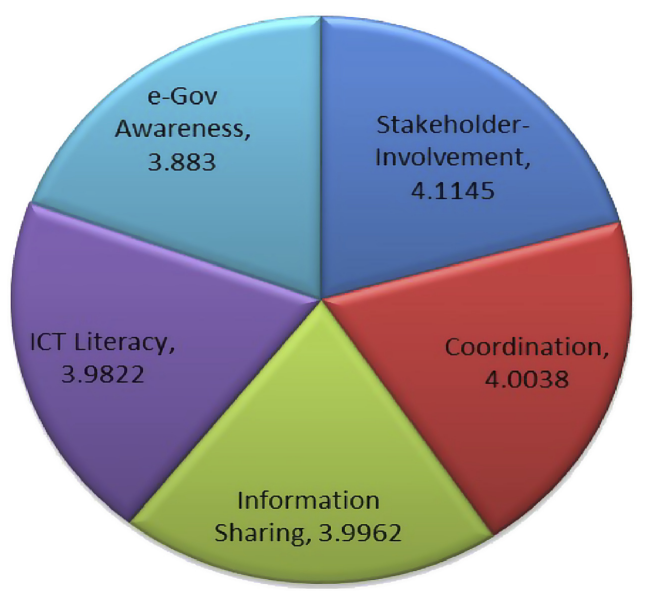


printed media, written reports of activities and initiatives and dissemination through magazines and newspapers. The use of electronic media, particularly radio, can speedily disseminate information and share knowledge among people. Additionally, an agency's website through social media presence (Facebook, Twitter and so on) can be used to publicize the progress of the initiative. This can improve knowledge sharing among both citizens and within the government.

ICT literacy is the fourth major challenge identified by our respondents. The literacy level can be increased throughout the government and private sector as well with the commencement of training programs for government employees, business communities, social and civic communities, farmers, military units, students and the private sector as is done by the Government of South Korea. Publicity for such training (and perhaps the training itself) can utilize television, radio and other mass media. Training can be delivered through video conferences at the contemplated telecenters.

e-Government - Awareness, according to our analysis, is the fifth major obstacle in implementing e-Government. According to the experience of developed and developing countries, it is critical to improve e-Government awareness among government agencies and citizens; it will directly help in the adoption of e-Services. Awareness could be improved by using various channels such as radio, television, advertisements, mobile application and social media.

\section{Theoretical implication}

The studies conducted previously on e-Government and referenced herein highlighted implementation challenges in developing countries as a group. Applying this study to Afghanistan may contribute to our understanding of key challenges being faced in implementing the e-Government process, specifically in our country. The current study contributes some significant findings to the academic field of studying the e-Government implementation challenges. It adds support and information from the public and private sector's perspectives regarding major challenges in e-Government implementation in Afghanistan.

\section{Concluding remarks and future works}

Governments around the world are under pressure from rapid globalization, fiscal, social and technological changes to provide services that are citizen-centric, efficient, transparent, and effective, and one-stop, any time and nonstop. Post-conflict countries are under even greater pressure to create such services because they replace the vacuum caused by the violence and will be the only services offered, rather than simply an upgrade of current government offerings that already meet citizen needs. The adoption of technology is the most efficient way to integrate the public and private sector and to provide services with accountability, transparency and efficiency, but this is not an easy task, especially for developing countries.

This research looked at (a) e-Government implementation challenges in developing countries and particularly in Afghanistan. A literature review shows many challenges common among developing countries: a lack of ICT literacy, incomplete infrastructure, a digital divide existing between the rural poor and the emerging urban middle class, the uncertainty about data privacy and data security, the absence of comprehensive ICT policies and legislation, lack of an ICT culture in government and the traditional components of the economy, questions regarding the government's ongoing financial commitment to the project, e-Government awareness, willingness of ministries to engage in information sharing, a void of ICT leadership outside the technologically oriented Ministries, resistance to change,

Prospects of e-Government implementation 
ITPD

5,1

\section{8}

a historic lack of intergovernmental coordination and low stakeholder involvement are just some of the many challenges identified.

The survey questionnaires were developed based on the challenges found in the literature review. The survey questionnaire translated into national languages (Pashto and Dari), and an English version served as a control indicator followed by a local translator expert. At first, a pilot version of the survey had been sent to 10 officials from the Ministry of Communication and IT. After the attesting period, the survey was circulated to 150 respondents who were experts in various fields such as Information Management, General Management/ Administration and IT in Afghanistan.

All respondents agreed that stakeholder involvement, coordination, information sharing, ICT literacy, awareness, resistance to change, ICT, finance issues, ICT policy, leadership, data privacy, legislation, ICT culture and digital divide are some of the major challenges for e-Government implementation in Afghanistan. Respondents (3.1412) on ICT security were impartial in their response on whether to include this indicator into challenges. Many projects are run by the Ministry of Communication and IT and with the completion of these projects most of the challenges identified in the analysis of the quantitative survey could be addressed; meanwhile, the government is also vigorously pursuing legal and policy modifications. Most research records numerous limitations, therefore, it is important to note that this study is no exception. Some of the limitations were recorded in the course of the study will be counted for the purpose of placing the finding in the right perspective.

The limitations of this study were time constraints and difficulty to generate enough participation in the survey. In light of these constraints, I did a quantitative survey but could only include very few members of the top management. Second, the study is limited due to the lack of participation by respondents from various sectors such as citizens, university students, academia, banks, businesses and NGOs. The third limitation was the lack of research materials for this study. Many difficulties were encountered with respect to finding materials of previous research studies on the topic and in particular in the context of Afghanistan.

This study was focused on delineating the factors which are hampering implementation of e-Government in developing and post-conflict countries with the emphasis on its implications in Afghanistan. Based on the limitations and findings from the study, several suggestions may be proposed for future research as following:

The research study only collected data from limited numbers of experts (CIO, IT, and Management experts) from the government and the private sector due to time limitations and resources. It would be desirable to cast the net wider and get the views of both the general public and members of the students body and non-management sectors regarding their opinion on what they perceive as critical impeding factors for e-Government implementation.

Data collection was mostly limited to organizations based in Kabul city, which excluded provincial institutions. Therefore, a study could be carried out to cover a more geographically diverse population to ascertain the validity of the factors and their variables in smaller cities and rural areas where the federal presence (and the concept of government generally) is less pervasive.

As this study only focused on government and private sector management, further studies can be done with the involvement of NGO's, banks, academia, political parties and civil societies.

With all the obstacles mentioned above the environment around us across the country is such that other media websites particular international and local news, governments and people utmost needed links regarding help and education ads and comments via Facebook, TVs Apps, Newspapers, etc., made e-Government attractive to every walk of life. Mostly all vacancies and ads both across government, private, and independent authorities are 
announced via the Internet. People looking for a job of their likes or any job in any administrative setups simply open the web either directly via their mobile or Laptops, desktop computers in their house or offices or any Net Cafes fill the forms and send where they want. We are also having an e-Passport; e-Working permit, licenses verification and Postal tracking systems in addition to this in near future all 34 provinces will have an e-NID (National ID) registration centers and, people would be able to- get their IDs, on the due date and time without any hassle.
Prospects of e-Government implementation

\section{Notes}

1. "Business process reengineering (BPR) is the analysis and redesign of workflow within and between enterprises" (http://searchcio.techtarget.com/definition/business-process-reengineering).

2. Leadership, Resistance to change, Information sharing, collaboration, Stakeholder engagement and legal impact.

3. ICT culture, Digital divide, Awareness and ICT literacy.

4. Infrastructure, Finance, Policy, Security and Privacy.

\section{References}

Al-Rashidi, H. (2010), "Examining internal challenges to e-government implementation from system users perspective", European and Mediterranean Conference on Information Systems, Vol. 2010, p. 8, EMCIS2010.

Alam, M. (2007), "E-governance: scope and implementation challenges in Bangladesh", International Conference on Theory and Practice of Electronic Governance, ICEGOV, Macao.

Basu, S. (2004), "E-government and developing countries", International Review of Law, Computers and Technology, Vol. 18 No.1, pp. 109-132, MARCH 2004, 25.

Dada, D. (2006), "The failure of e-government in developing countries", The Electronic Journal on Information System in Developing Countries, Vol. 10, pp. 3, 5.

Dardha, N.V. (2004), "E-government for developing countries: opportunities and challenges", The Electronic Journal on Information Systems in Developing Countries, p. 24, available at: http: www.ejisdc.orgs, University of BORA; School of Business and Informatics, www.hb.se/ida.

Drew, M.A. (2010), "Implementation of e-government: advantages and challenges", IASK E-ALT2010 Conference Proceedings.

Drljaca, D.P. and Latinović, B. (2012), "E-governance in republic of SRPSKA - challenges and prospects", Quality of Life, Vol. 3 Nos 1-2, pp. 32-40, 33,35.

Heeks, R. (2003), Most E-Government-for-Development Projects Fail: How Can Risks be Reduced?, Government Working Paper Series.

Hwang, M.S., Li, C.-T., Shen, J.J. and Chu, Y.-P. (2004), "Challenges in e-government and security of information”, Information and Security: An International Journal, Vol. 15 No. 1, pp. 12, 13.

ITU (2008), "Electronic government for developing countries", available at: www.itu.int/ITU-D/cyb/ app/e-gov.ht.

Khan, S. (2009), "ICT and education in Bangladesh", [Online], available at: fromsaburkhan.infohttp:// saburkhan.info/index.php?Option-com-content\&view-article\&id=358:ICT-and-education-inBangladesh\&catid=44:iteducation\&Itemed $=73$ (accessed 5 December 2009).

MCIT (2013), available at: https://mcit.gov.af/sites/default/files/2018-12/EGOV\%20AF $\% 20 \%$ 20Electronic $\% 20$ Government $\% 20 \% 20$ Strategy $\% 20$ in $\% 20$ Afghanistan.pdf (accessed 7 June 2020), from Ministry of Communications and IT: https:/mcit.gov.af/.

Ndou, V.D. (2004), "E-government for developing countries: opportunities and challenges", The Electronic Journal of Information Systems in Developing Countries, Vol. 18 No. 1, pp. 1-24. 
ITPD

5,1

Nkwe, N. (2012), "E-government: challenges and opportunities in Botswana", International Journal of Humanities and Social Science, Vol. 2 No. 17, pp. 41, 46.

OECD (2013), "Implementing e-government in OECD countries", Vol. 9, available at: http:// webdomino1.oecd.org/COMNET/PUM/e-Govproweb.nsf.

Qaisar, N. and Khan, H.G. (2010), "E-government challenges in public sector: a case study of Pakistan", IJCSI International Journal of Computer Science Issues, Vol. 7 No. 5, pp. 3-5, 6, 8.

Rangarirai Matavire, W.C. (2010), "Challenges of e-government project implementation in a South African context”, Electronic Journal of Information Systems Evaluation, Vol. 13 No. 2, 2010, pp. 153-164, 12.

Tele-community, A-P (2012), E-government Implementation in Asia-Pacific Developing Countries and its Challenges and Obstacles, Vol. 5, ASTAP/REPT, Bankok, ASTAP20, Bangkok, 2012.

United Nation, U (2012, 2014, 2016, 2018, 2020), “E-Government Survey”, United Nation Department of Economic and Social Affairs, available at: https://publicadministration.un.org/egovkb/en-us/ Data/Country-Information/id/1-Afghanistan/dataYear/2020.

UNU-IIST (2008), UNeGov.net school on Foundation, Planning Module-Kabul, Afghanistan (PPT file -UNDESA, OECD 'e-Gov Maturity'), Kabul.

Weerakkody, V., Dwivedi, Y.K. and Kurunananda, A. (2009), "Implementing E-government in Sri Lanka: lessons from the UK", Information Technology for Development, Vol. 15 No. 3, pp. 181-184, 186.

Zamira Dzhusupova, T.J. (2011), "Sustaining electronic governance programs in developing countries", Proceedings of the European Conference on E-Government, Vol. 2011, p. 203, 12.

Zeleti, F.A. (2010), "The progress and obstacles of implementing and improving e government", Islamic Republic of Iran, Lappeenranta University of Technology, Lappeenranta.

\section{Further reading}

Cechini, S. and Raina, M. (2004), "Electronic government and the rural poor: the case of Gyandoot", Information Technologies and International Development, Vol. 2 No. 2, pp. 65-75.

Paul, T. and Jaeger, K.M. (2003), E-government around the World: Lessons, Challenges, and Future Directions, USA: Florida State University, School of Information Studies, Information Use Management and Policy Institute, Tallahassee, FL.

\section{Appendix}

The appendix is available online for this article.

\section{Corresponding author}

Abdul Mateen Samsor can be contacted at: mateen.samsor@gmail.com

For instructions on how to order reprints of this article, please visit our website:

www.emeraldgrouppublishing.com/licensing/reprints.htm

Or contact us for further details: permissions@emeraldinsight.com 